\title{
¿ES VÁLIDO EL USO DE LA BATERÍA EN EL TEMPLO COMO PARTE DEL CULTO A DIOS?
}

\author{
ERIK JimÉnEz MiLla \\ Docente de LA FACULTAD DE TEOLOGIA - UPEU
}

\section{Introducción}

La liturgia adventista está siendo desafiada por estilos contemporáneos de adoración. Es suficiente revisar las colecciones de muchos intérpretes musicales para ver la influencia de los ritmos contemporáneos.

¿Podemos como iglesia revisar y contextualizar nuestra liturgia? Si esto es posible, ¿qué principios revelados deberían guiar nuestras decisiones al enfrentar estos cambios?

El presente artículo tiene el objetivo de revisar la validez o invalidez del uso de la batería en el templo como parte de la adoración. Si la batería es la que puede cambiar el cómo uno percibe un determinado canto, se hace indispensable este estudio.

La pregunta que da inicio a esta investigación deriva de la incertidumbre del uso del tambor y la danza en la Biblia, ya que los tambores fueron usados por el pueblo de Israel (2 Sam 6:14,15). ¿Esto valida el uso del tambor moderno (la batería) en el templo y como consecuencia los movimientos, tipo danza o baile? Frente a esta posible interpretación, el desarrollo de este artículo es importante.

Como hipótesis, la influencia de la cultura egipcia, en cuanto a adoración, influyó en la cultura israelita, la que involucró elementos que se usaban en Egipto para la alabanza a sus deidades, y al final llegaron a ser parte de la cultura del mismo pueblo de Dios. Es así como Dios, teniendo la paciencia necesaria, llevó al pueblo hacia un cambio radical, utilizando a un gran músico, David, quien en sus comienzos, actuó como actuaban sus contemporáneos; después de que Dios le mostró el camino correcto, estableció la forma como Dios espera recibir la alabanza. Para ello eliminó el tambor de la alabanza, y al quitar el tambor, también la 
danza quedó al margen. Después de que David estableciera cuáles eran los instrumentos de Dios, no más se menciona a ningún personaje bíblico danzando y haciendo uso del tambor como parte de la alabanza.

La metodología a seguir es histórica descriptiva, porque se verá en la historia bíblica los elementos que ayuden y conecten lo relacionado con el uso de instrumentos en la Biblia. ${ }^{1}$ Se tratará de encontrar cuál es el momento cuando se dejó de danzar, y, por ende, usar el tambor en la alabanza. También hay que reconocer el análisis que dos colegas hicieran como requisito para una de las materias de posgrado titulado "Música y adoración de la Iglesia Adventista del Séptimo Día. ${ }^{2}$

\section{La música en la Biblia}

Los defensores de la música secular en el culto religioso sustentan sus argumentos en eventos bíblicos que hablan de personas alabando a Dios con músicas seculares y con danzas. Afirman que no hay posibilidades de establecer diferencia entre la música secular y la música de adoración, ya que ambas eran dirigidas a Dios, con vista a adorar.

Una lectura atenta de los eventos involucrados al culto en Israel lleva a la conclusión de que Dios recibió el loor al son de la música secular y al ritmo de danzas. Permite también concluir que él tomó providencias para conducir a Israel a una renovación cultural también en el área de la música.

Después de pasar el mar rojo, María y las mujeres de Israel adoraron a Dios con cánticos acompañados de tambores y danzas. (Ex 15:2021). En circunstancias festivas, David danzaba delante del Señor (2 Sam $6: 14,15)$. Había profetas en Israel que profetizaban al son de la música, acompañada de tambores (1 Sam 10:5). El Salmos 150:4 exhorta loar al Señor con "adufe", entre otros instrumentos y con "danzas". Sobre

${ }^{1}$ Elena G. de White, Joyas de los testimonios (Buenos Aires: Asociación Casa Editora Sudamericana, 1970), 3: 28.

${ }^{2}$ Apuntes de clase de Vinicio Núñez y Walter Alaña sobre la "Música en la Adoración de la Iglesia Adventista del Séptimo Día" en el curso: "Asuntos contemporáneos" en la Maestría en Teología dictado en la Universidad Peruana Unión, Febrero 2004. En este trabajo se presenta los principios de adoración en la alabanza y en una de sus secciones se analiza el uso de los instrumentos en el templo. 
la base de estos textos, Souza Joao afirma, precipitadamente, que "la adoración a Dios no se puede separar el llenarse de júbilo con danzas" y concluyó que "David representa aquí a aquellos hermanos renovados (pentecostales) que, restaurados en su adoración, danzan delante del Señor.

Es preciso notar que la música de tambor y las danzas eran comunes en circunstancias festivas en que se conmemoraban victorias, una especie de fiesta secular. Así de la misma forma, María danzó delante del Señor, al son de tambores, la hija de Jefté danzó delante del padre (Jue 11:34), las mujeres de Israel danzaban delante de Saúl y de David (1 Sam 18:6; 21:11), y el pueblo danzó delante del becerro de oro (Ex 32: 19).

\section{La batería y la música en el templo}

La presencia y la ausencia del tambor, en circunstancias bíblicas específicas, ayudan a comprender la pregunta del uso de la batería en la adoración a Dios.

En la conducción del arca de Quiriat a Jearim hasta la casa de Obed Edom, hubo música con tambores, David danzó y se alegró al ritmo de banda (2 Sam 6:5 y 1 Cr 13:8). En ese viaje, todo se dio equivocado. De la misma forma que "vino" feliz Nadab y Abiu ignorando las orientaciones divinas en cuanto al templo (Lv 10:1,9), el ritmo de fiesta de David, a pesar de que sólo los levitas podían conducir el arca, y Uza ignoró que no podía tocarla, los bueyes tropezaron, el arca casi cayó y Uza murió herido por el Señor (1 Cr 13:9-10). David temió y se preguntó. ¿Cómo traeré el arca a mí? (1 Cr 13:12). Tres meses después, el rey juntó al pueblo para buscar el arca de la casa de Obed Edom. En esta vez, él orientó que nadie conduciría el arca, sino sólo los levitas (1 Sam 15:2). Hubo alegría, al contrario del primer intento; esta vez, la banda musical no tuvo tambores, sí en cambio arpas, liras y címbalos (1 Cr 15:16). El traslado fue un éxito.

La música durante el transporte del arca a Jerusalén, sin uso de tambores, fue llamada la "música de Dios" (1 Cr 16:41-42), mientras que la banda que tocó al ritmo de danza, cuando Uza murió, no recibió ese adjetivo, en el libro escrito por el mismo autor (1 Cr 13:8).

David quiso hacer una casa para Dios, mas no le fue permitido. 
El rey era músico y Dios le dio orientaciones, para que tomase todas las providencias para el templo que Salomón edificaría. Entre esas orientaciones, Dios determinó los instrumentos (címbalos, liras y arpas) que deberían ser parte de la música del templo. En 2 Crónicas 29: 25 se registra el edicto que los levitas fueran establecidos "en la casa del Señor con címbalos, liras y arpas...porque este mandato vino del Señor, por intermedio de sus profetas". David dio los instrumentos para ser utilizados por los levitas. Es significativo que esos instrumentos son referidos en 2 Crónicas 7: 6 como "los instrumentos musicales del Señor" que el rey David había dicho para utilizar en las acciones de gracias al Señor. El artículo plural definido "los" indica un grupo específico de instrumentos, calificados como "del Señor".

La lista de esos instrumentos aparece en diversas ocasiones, siempre sin inclusión del tambor o adufe (pandereta) (1 Cr 16:5; 25:1; 6; 2 Cr 5:12-13). En la purificación del templo, emprendida por Ezequías, los músicos levitas son colocados en su función como los instrumentos hechos por David. En la ceremonia, la música de estos instrumentos son otra vez llamados “cánticos del Señor” (2 Cr 29:27). Los únicos instrumentos que aparecen en las listas de los usados en el templo que fueron hechos por David, son las trompetas (2 Cr 5:12-13; 29:27).

La exclusión del tambor en el templo puede indicar que Dios no quiso el instrumento en la música de adoración, por causa de su relación directa con el misticismo pagano y, por su influencia, en el sentido de excitar las danzas y embotar la conciencia y el juicio.

El ritmo del tambor que inclinaba a las personas a la danza debería estar fuera del culto que requiere la lucidez de la mente para la comprensión de la voluntad de Dios. Además de esto, el templo era una representación del santuario celestial y del trono de Dios; la música usada allí debería distinguirse de aquella usada en las celebraciones profanas. Helen G. Grauman ${ }^{3}$ afirma que ciertos instrumentos como el tambor, que podían ser incluidos en las procesiones, fueron excluidos de la planeada orquesta del templo. Esos instrumentos tenían asociaciones seculares.

${ }^{3}$ Helen Grauman, A Música em Miha Bíblia (Santo André, SP: Casa Publicadora, 1968), 86. Citado en Dorneles, 193. 
Martín Stefani ${ }^{4}$ considera que el ritmo, producido más propiamente por el tambor, es la característica más eminente y esencial de la música africana, ya ampliamente relacionada con las experiencias de transe y posesión. Gilbert Rouget ${ }^{5}$ también señala el papel del ritmo con las experiencias de transe. Para él, el ritmo, en acelerando y crescendo, producido por cualquier instrumento, y no sólo por el tambor, responde a las experiencias místicas.

\section{Influencia en el templo}

Los relatos bíblicos sobre la música, posteriores a la inauguración del templo, pueden sugerir qué tipo de influencia y cultura musical del templo ejerció sobre el pueblo de Israel. En el libro de Isaías, hay juicios pronunciados contra personas que celebraban fiestas con embriaguez y música con tambores (ver. 5: 12; 24: 8 y 9). Después de la vuelta del cautiverio babilónico, la adoración fue conducida de modo semejante a lo que fue en el templo de Salomón. Los mismos instrumentos son usados, también con excepción del tambor, ese criterio es relacionado con las determinaciones de Dios dadas a David (Esd 3:10). En la ceremonia de dedicación de los muros de Jerusalén, hubo música de adoración a Dios, usando címbalos, liras y arpas (Neh 12:27), el mismo patrón del templo de Salomón. Isaías registra la expectativa de salvación, cuando se estará en la casa del Señor, loando con "instrumentos de cuerdas" (Is 38:20).

La iglesia cristiana del Nuevo Testamento, es rica en loor y adoración, mas en ningún momento son mencionados cánticos acompañados de danzas al ritmo de tambor, el que se sugiere es el patrón del templo, distinto del patrón profano, tornándose un modelo para todas las reuniones sagradas. El de los cristianos es llamado "cánticos espirituales" y "sacrificio de loor" (Col 3:16; Ef 5:19; Heb 3:15). En el contexto del Nuevo Testamento, la flauta es mencionada 4 veces (Mt 9:23; 11:17; Lc 7:32; 1 Co 14: 7); las trompetas, 20 veces; arpas 3 , y adufe o tambor, ninguna vez.

${ }^{4}$ Martín Stefani, Música Sacra, Cultura y Adoración, $2^{\mathrm{a}}$ ed. (Engenheiro Coelho, SP: Imprensa Universitaria Adventista, 2002), 138, citado en Dorneles, 193.

${ }^{5}$ Gilbet Rouget, Music and Trance: A Theory of the Relations between Music and Possession (Chicago: University of Chicago, 1986), 78-86, citado en Dorneles, 193. 
La música con danzas es mencionada apenas en celebraciones seculares (Lc 15: 25). La "danza" tiene relación con el "tambor", porque sin éste es imposible crear danza.

Los eventos posteriores al templo parecen indicar que la adoración en Israel; después, en la iglesia cristiana, se apartó de las costumbres profanas y se concentró en el patrón presentado por Dios. Las visiones del Apocalipsis que mencionan la adoración en el cielo (Ap 5:8-14; 7:11$12 ; 11: 16 ; 14: 2 ; 15: 2 ; 19: 4)$, están sin ninguna referencia a danzas o a tambor, parecen confirmar que el modelo asimilado, a partir del templo de Salomón, es el modelo del celestial.

La adoración bíblica, que permea el concepto de una santidad inteligente, envuelve al ser humano completo, especialmente a su mente. La razón y el discernimiento son instrumentos indispensables en el culto una vez que "al hombre no le es posible conocer a Dios fuera del uso de su mente". Además de eso, "el principio fundamental de genuina adoración es que debemos conocer a Dios antes de poder adorarlo".

\section{Orientaciones de Elena G. de White}

Se dan muchos consejos sobre este tema. Algunos de ellos son:

\section{Entusiasmo saludable}

Los servicios del culto no deben ser fríos y aburridos. Elena de White dice que hay un entusiasmo saludable, ¿qué es un entusiasmo saludable?

El Espíritu Santo de Dios es el único que puede crear un entusiasmo saludable. Dejad que trabaje Dios, y que el instrumento humano ande humildemente delante de él, velando, esperando, orando, contemplando a Jesús a cada instante, siendo guiado y controlado por el precioso Espíritu que es luz y vida. ${ }^{6}$

Un entusiasmo saludable es una alegría santa expresada en alabanza y culto. El ser humano debe caminar suave y reverentemente en la presencia del gran Creador y Redentor.

\section{Experiencia espiritual basada sobre la Palabra}

Excitación no es santificación. Únicamente la completa conformidad con la voluntad de nuestro Padre que está en el cielo es santi-

${ }^{6}$ Elena de White, Mensajes Selectos (Boise, Idaho: Publicaciones Interamericanas, 1967), 2:108-9. 
ficación, y la voluntad de Dios está expresada en su santa ley. La observancia de todos los mandamientos de Dios es santificación. Evidenciar que somos hijos obedientes a la Palabra de Dios es santificación. La Palabra de Dios debe ser nuestra guía, no las opiniones o ideas humanas. Los que han de ser verdaderamente santificados, escudriñen la Palabra de Dios con paciencia, con oración, y con humildad y contrición de alma. Recuerden que Jesús oró: "Santifícalos en tu verdad; tu palabra es verdad" (Juan 17: 17). ${ }^{7}$

La experiencia espiritual se basa sobre la Palabra de Dios antes de que en experiencias de éxtasis. La señora White da mensajes fuertes a quienes buscan un alto nivel emocional a través de una "experiencia espiritual".

\section{El Espíritu Santo no está presente en el alboroto y el ruido}

La siguiente declaración no sólo es útil en la precaución que da, sino es un instructivo acerca de lo que Dios aprueba:

La forma cómo se han celebrado las reuniones en Indiana, con ruido y confusión, no las recomienda a las mentes concienzudas e inteligentes. Estas demostraciones no contienen nada capaz de convencer al mundo de que poseemos la verdad. El ruido y el alboroto en sí mismos no constituyen ninguna evidencia en favor de la santificación, o del descenso del Espíritu Santo. Vuestras demostraciones extravagantes crean únicamente disgusto en las mentes de los no creyentes. Cuanto menos haya de esta clase de demostraciones, tanto mejor será para los participantes y para el pueblo en general. ${ }^{8}$

\section{Argumento científico}

La ciencia demuestra que la música "dicta sentimientos", algo comprobado por la fisiología, la psicología y la sociología, y muy explotado, entre otros, por la música militar y por el cine donde se adaptan músicas para diversos tipos de escenas. La música se graba en la parte del cerebro que normalmente es estimulada por las emociones, evitando

${ }^{7}$ White, Mensajes Selectos , 3: 204.

${ }^{8}$ Ibíd., 2: 39. 
los centros del cerebro relacionados con la inteligencia y la razón. ${ }^{9}$

Antes de que el mensaje codificado llegue al cerebro, el conducto nervioso atraviesa una zona sumamente importante donde se encuentran el tálamo y el hipotálamo, así como el cerebelo. El mensaje nervioso producido por una música con un ritmo pesado favorece la secreción de varias glándulas, entre las cuales citamos la tiroides y las glándulas sexuales. Antes de llegar al cerebro, el flujo nervioso pasa por el cerebelo; éste es el centro de la coordinación de los movimientos. ${ }^{10}$

\section{Conclusión}

Se vive en tiempos controversiales e importantes cuando las personas y sociedades expresan sentimientos religiosos sin una guía cristiana clara y bíblica. La música ha llegado a ser un asunto importante, requiriendo discernimiento espiritual y decisión.

Quienes acogen fundamentos bíblicos como los de David, deberían ser más concienzudos en su investigación bíblica, porque con una simple hermenéutica, se darían cuenta de que esos pretendidos fundamentos, no son válidos. Los principios no se ven en un simple periodo sino deben permear el todo de la Biblia. Si la danza era lo apropiado, los profetas y apóstoles hubieran dado la validez necesaria, para que hoy nosotros la podamos considerar como algo indispensable para la adoración a Dios.

La ausencia del tambor en la relación de instrumentos en el templo, determina la imposibilidad hoy de creer que Dios se agrada de que en el templo haya una batería, que bajo su ritmo constante y los movimientos de quien la ejecuta, agregados al movimiento rítmico que genera en la hermandad adoradora, sea indispensable para la alabanza a su nombre.

Considerando que hoy en día en muchas iglesias cristianas la

${ }^{9}$ Enrique Treiyer, "El cristiano y la música" en Revista Estrategias para el cumplimiento de la misión (Agosto 2003), 42-56. El artículo del Dr. Treiyer está basado principalmente en la obra de Samuele Bacchiocchi, (ed.), The Christian \& Rock Music - A Study on Biblical Principles of Music (Berreen Springs, MI: Biblical Perspectivas, 2000). Para una respuesta a la obra de Bachiochi y a favor de la Música Cristiana Contemporánea ver Ed Christian, Joyful Noise: A Sensible Look at Christian Music (Hagerstown, MD: Review and Herald, 2003).

${ }^{10}$ Ibíd. 
batería es la que produce un ruido "agradable" para la juventud, y las "pistas" o "play backs" contienen un alto contenido de la batería; se invita, a través de este artículo, a una reflexión profunda de lo que se está haciendo o lo que se pretende hacer en la adoración a Dios. Esta reflexión es especialmente para quienes toman el liderazgo de la música, sin tener en cuenta los principios bíblicos y del espíritu de profecía, prefieren hacer prevalecer sus gustos personales y las "políticas" empresariales para agradar a los hombres, pero no a Dios.

Así como los israelitas cuando andaban por el desierto alegraron su camino con la música del canto sagrado, Dios invita a sus hijos de hoy a alegrar por el mismo medio su vida de peregrinaje. Pocos medios hay más eficaces para grabar sus palabras en la memoria, que el de repetirlas en el canto. Y un canto tal tiene poder maravilloso. Tiene poder para subyugar naturalezas rudas e incultas; para avivar el pensamiento y despertar simpatía; para promover la armonía de acción y desvanecer la melancolía y los presentimientos que destruyen el valor y debilitan el esfuerzo (1903). ${ }^{11}$

La música forma parte del culto tributado a Dios en los atrios celestiales, y en nuestros cánticos de alabanza debiéramos procurar aproximarnos tanto como sea posible a la armonía de los coros celestiales. El canto, como parte del servicio religioso, es un acto de culto como es la oración (1890). ${ }^{12}$

El uso de instrumentos musicales no es de ninguna manera objetable. Estos se utilizaron en el servicio religioso en la antigüedad. Los adoradores alababan a Dios por medio del arpa y el címbalo, y la música debiera tener su lugar en nuestros cultos (1898). ${ }^{13}$

${ }^{11}$ White, La educación, 163.

${ }^{12}$ White, Patriarcas y profetas, 645.

${ }^{13}$ White, Evangelismo, 365. 